\title{
KONSEPSI PENDIDIKAN ISLAM DALAM PENINGKATAN KUALITAS SUMBER DAYA MANUSIA
}

\author{
Oleh: \\ Abd. Wahid HS1 \\ Email: abdwahidhs06@gmail.com
}

\begin{abstract}
Education is one of the central concerns of Muslims. Islamic education is the guidance of spiritual and physical growth according to the teachings of Islam with the wisdom of directing, teaching, training, nurturing and supervising the enactment of all Islamic teachings. The ultimate goal of Islamic education is the creation of human beings (perfect human beings), are human beings capable of harmonizing and meeting the needs of the world and the hereafter and the physical, psychological, social, and spiritual needs. So the orientation of Islamic education in addition to fulfilling shortterm life needs such as the fulfillment of worldly needs also meet the long-term life needs such as fulfillment needs in the hereafter. The essence of Islamic education is an endless process in line with the universal consensus established by Allah and His Messenger
\end{abstract}

Keywords: education, Islam, quality, human resources

\section{Pendahuluan}

Manusia dalam pandangan Islam adalah mahluk unggulan yang dikarunia akal kreatif sehingga memungkinkannya untuk mengembangkan peradaban dan kebudayaannya (Al-Isra': 70). Dengan potensi akal pikirannya manusia mengatasi persoalan kehidupannya secara matematis menurut asas-asas penalaran deduktif dan induktif. Dengan potensi rasa manusia mengatasi persoalan kehidupannya dengan pendekatan estetik menurut asas perimbangan. Dengan potensi karsa,

${ }^{1}$ Dosen Program Studi Pendidikan Bahasa Arab STAI Syaichona Moh. Cholil Bangkalan Madura. 
manusia mengatasi persoalan kehidupannya melalui pendekatan prilaku menurut asas-asas etika. ${ }^{2}$

Keunggulan manusia tersebut dengan potensi yang dimilikinya dan izin yang diberikan oleh Allah kepadanya, manusia akan dapat melampaui keunggulan malaikat dan mahkluk hidup lainnya, bahkan gunung-gunung dan benda benda langitpun akan disaingi oleh kehebatan potensi sumber daya manusia. Meskipun manusia itu kerap kali terjebak oleh sikap egoisnya dan tindakan-tindakannya yang spekulatif.

Manusia berdasarkan al-Qur'an, diciptakan oleh Allah dari dua komponen strategis, yaitu: pertama adalah komponen materi, dari ekstrak tanah (sulaallah min thin). Kedua, adalah komponen yang non-materi, yang memiliki kekuatan fungsional untuk menghubungkan manusia dengan Tuhan yang disebut ar-ruh, suatu subtansi yang tetap misterius, dalam arti belum terungkap jelas, tentang hakikatnya, sistem kerjanya, maupun mobilitasnya. Bahkan Allah sendiri menyatakan bahwa ar-ruh itu merupakan monopoli kompetensi-Nya, sedangkan manusia yang terbatas ini hanya dapat mengetahuinya dalam ukuran yang minimal sekali. ${ }^{3}$

Kualitas kemakhlukkan manusia yang demikian itu diakui oleh makhluk Allah Swt yang lain kecuali iblis, yang menyatakan dirinya lebih mulia daripada manusia (Adam) dan menetang perintah Allah SWT untuk hormat kepada Adam.

Pada hakikatnya kehadiran manusia dalam kehidupannya sejak Adam As sampai akhir zaman nanti, adalah menunaikan tugas esensial, yang berupa: (a) tugas ibadah, dalam arti terbatas maupun luas, dan (b) tugas khilafah, sebagai mandataris Tuhan untuk mengatur kehidupan di atas muka bumi, mempelajari, mendayagunakan, mengkonservasi kekayaan dan sumberdaya alam. Sayyid Muhammad 'Alawi Al Maliki menjelaskan, bahwa Allah Swt menciptakan manusia dan keturunannya sebagai khalifah di muka bumi, yang bertugas memakmurkan dengan nilai-nilai kebaikan, keutamaan, dan petunjuk. Agar manusia dapat menegakkan keadilan, persamaan, kasih saying, rahmat, pembelaan terhadap golongan

\footnotetext{
${ }^{2}$ Suhartono, Suparlan.2005.Filsafat Ilmu Pengatahuan.Jogjakarta:AR-RUZ, hlm. 40

3 Tholhah Hasan, Muhammad.1995.Makalah Seminar Nasional Pendidikan oleh PP.Lembaga Pendidikan Ma'arif, hlm. 1-2
} 
yang lemah, membantu orang yang tertindas, mengarahkan masyarakat sekuat kemampuannya agar terwujud kehidupan yang bahagia dan sejahtera. ${ }^{4}$

Untuk kerberhasilan tugas-tugas tersebut dan kemaslahatan hidup manusia itu sendiri, Allah tidak melepaskan manusia hidup di dunia ini semata-mata mengandalkan kekuatan yang bersumber pada potensipotensi yang sudah tersimpan pada dirinya sendiri (fitroh mukhallaqah), ${ }^{5}$ tetapi dilengkapi dengan bimbingan spiritual, doctrinal, dan informatif melalui wahyu yang diterima Rasul (fitroh munazzalah), yang dalam aktualisasinya kita kenal dengan sebutan agama (al-Rum: 30).

Kemampuan mengingat kepada Allah (dzikrullah), merupakan indikasi adanya hubungan antara manusia dengan Tuhan, dan kualitas hubungan ini akan ditentukan oleh intensitas dzikir yang dilakukan oleh manusia itu sendiri, dengan berbagai macam cara penampilannya. Di dalam konteks inilah Islam dengan tegas menyatakan peran Tuhan bagi manusia. Jika mengingat kepada Allah dan adanya kesadaran manusia tentang adanya Tuhan dan peranan-Nya, akan membuat kehidupannya mempunyai arti dan tujuan. "Janganlah engkau seperti orang-orang yang melupakan Allah, sehingga Dia menjadikan mereka lupa kepada diri mereka sendiri. Merekal itulah orang-orang yang sesat." (al-Hasyr: 19). Seruan al-Qur'an ini tertuju baik kepada kehidupan individu maupun kolektif.

\section{Konsep Pendidikan Islam}

Pendidikan adalah salah satu perhatian sentral umat Islam, baik dalam negara mayoritas muslim maupun minoritas muslim. Tujuan, wawasan, sistem dan kelembagaan pendidikan, yang dilaksanakan oleh dan untuk masyarakat muslim merupakan hal penting yang mempunyai tanggung jawab langsung terhadap masa depan umat Islam.

Terminologi "pendidikan Islam" berarti suatu proses yang komprehensif dari pengembangan kepribadian manusia secara

4 Abdusshomad, Muhyiddin. 2005. Penuntun Qolbu (Kiat Meraih Kecerdasan Spiritual). Surabaya:Khalista, hlm. $22 \& 13$.

5 Abdul Mujib dan Mudzakkir Jusuf. 2006. Ilmu Pendidikan Islam. .Jakarta:Kencana, Hlm. 67 
keseluruhan, yang meliputi intelektual, spiritual, emosi dan fisik, sehingga seorang muslim disiapkan dengan baik untuk dapat melaksanakan tujuantujuan kehadirannya oleh Tuhan sebagai hamba dan wakilNya (hhalifahNya) di dunia. ${ }^{6}$ Proses ini melibatkan saluran-saluran formal maupun infornal yang dapat digunakan untuk pengembangan pribadi manusia.

Pendidikan Islam adalah bimbingan terhadap pertumbuhan rohani dan jasmani menurut ajaran Islam dengan hikmah mengarahkan, mengajarkan, melatih, mengasuh dan mengawasi berlakunya semua ajaran Islam". ${ }^{7}$ Pendidikan dalam pengertian ini diarahkan pada keseimbanagan antara pemenuhan kebutuhan dan perkembangan jasmani dan rohani melalui bimbingan, pengarahan, pengajaran, pelatihan, pengasuhan dan pengawasan yang kesemuanya dalam koridor Islam.

Tujuan akhir pendidikan Islam adalah terciptanya insan kamil (manusia sempurna), yaitu manusia yang mampu menyelaraskan dan memenuhi kebutuhan dunia dan akhirat dan kebutuhan fisik, psikis, sosial, dan spiritual. Jadi orientasi pendidikan Islam disamping untuk memenuhi hajat hidup jangka pendek seperti pemenuhan kebutuhan duniawi juga memenuhi hajat hidup jangka panjang seperti pemenuhan kebutuhan di akhirat kelak.

Dalam konferensi dunia tentang Pendidikan Islam yang pertama di Mekah pada tahun 1977, dirumuskan beberapa rekomendasi yang terkait dengan konsep pendidikan Islam, yaitu:

a. Konsep Islam tentang manusia yang mempunyai keluasan dan jarak yang tidak dimiliki oleh konsep-konep lain manapun tentang manusia. Karena manusia dalam konsep Islam dapat menjadi khalifatullah, dengan menanamkan dan mengaktualisasikan sifat-sifat Allah dalam dirinya.

b. Pengetahuan adalah sumber kemajuan dan pengembangan umat manusia, oleh karenanya Islam tidak meletakkan hambatan apapun terhadap upaya pencapaian pengetahuan itu.

${ }^{6}$ Putra Dauly, Haidar. 2004. Pendidikan Islam dalam Sistem Pendidikan Nasional. Jakarta: Kencana, hlm. 190

${ }^{7}$ Abdul Mujib dan Mudzakkir Jusuf ,Op. Cit., hlm. 36-37 
c. Jangkauan pencapaian dan penguasaan pengetahuan ini harus seutuhnya, dalam dimensi intelektual, spiritual maupun fisikal, karena tanpa demikian seseorang tidak dapat mempertahankan pertumbuhan yang seimbang.

d. Aspek-aspek spiritual, intelektual, moral, imajinatif, emosional dan fisikal, harus tetap diperhatikan dalam membentuk interelasi di antara displin-disiplin keilmuan, secara sistematis, terprogram, dan berjenjang.

e. Pengembangan pribadi dilihat dalam konteks hubungan manusia dengan Tuhan, manusia dengan sesamanya, dan manusia dengan alam. Karena itu pengorganisasian disiplin ilmu dan pengaturan subyeknya direncanakan dengan acuan manusia sebagai individu, manusia sebagai mahluk sosial dan manusia sebagai makhluk yang harus hidup dalam harmoni dengan alam sekitarnya. Kepribadian dan eksistensinya secara kolektif dan sebagai kesatuan yang alamiah diatur atau dipersiapkan oleh hubungannya dengan Tuhan.

Pendidikan Islam bertujuan mengembangkan pertumbuhan yang seimbang dari potensi dan kepribadian total mausia, melalui latihan spiritual, intelektual, rasional diri, perasaan, kepekaan fisik. Karena itu pendidika Islam seharusnya menyediakan wahana dan sarana bagai perkembangan manusia dalam segala aspeknya: spiritual, intelektual, imajinatif, fisikal, ilmiah, linguistik, baik secara individual maupun secara kolektif dan memotivasi semua aspek untuk mencapai kebaikan dan kesempurnaannya. Tujuan terakhir pendidikan Islam adalah perwujudan penyerahan mutlak manusia kepada Allah, pada tingkat individual, masyarakat dan kemanusiaan pada umumnya.

Konsep Islam tentang ilmu pengetahuan dan teknologi (dalam rangka pendidikan) tidak mengenakan penghalang dan pembatas pada ilmu pengetahuan teoritis, empiris atau terapan, kecuali pembatas yang menyangkut tujuan-tujuan terakhir dari iptek tersebut di satu pihak, dan dampak yang sebenarnya di pihak lain. ${ }^{8}$ Dalam pemahaman Islam, ilmu pengetahuam mempunyai fungsi ibadah dan dengan ibadah itu mausia

${ }^{8}$ Putra Daulay, Haidar. Op.Cit., hlm. 190 
semakin erat menjalin hubungan dengan Tuhan. Oleh karenanya menurut istilah, mencari ilmu pengetahuan dengan niat dan tujuan yang baik akan memperoleh perlindungan rahmat Tuhan dan dijanjikan pahala dari Tuhan, sebagaimana layaknya ibadah-ibadah yang lain. Proses pencarian ilmu dalam Islam adalah seumur hidup (dari ayunan sampai liang kubur). Dengan demikian maka upaya mengembangkan kualitas diri tidak terbatas oleh umur dan status. Hakikat pendidikan Islam merupakan proses tanpa akhir sejalan dengan konsensus universal yang ditetapkan oleh Allah Swt dan Rasul-Nya. Pendidikan yang terus-menerus dikenal dengan istilah min al mahdi ila al lahd (life long education). ${ }^{9}$ Dasar pendidikan Islam adalah tauhid. Melalui dasar ini dapat dirumuskan hal-hal sebagai berikut.

a. Kesatuan kehidupaan, yaitu anatara kehidupan duniawi menyatu dengan kehidupan ukhrawi. Sukses atau kegagalan ukhrawi ditentukan oleh amal duniawinya.

b. Kesatuan ilmu antara ilmu-ilmu agama dan ilmu-ilmu umum yang semuanya bersumber dari Allah.

c. Kesatuan iman dan rasio yang masing-masing dibutuhkan dan mempunyai wilayahnya sehingga harus saling melengkapi

d. Kesatuan agama. Agama yang dibawa oleh para nabi kesemuanya besumber dari Allah SWT, prinsip-prinsip pokoknya menyangkut akidah, syari'ah, dan akhlak tetap sama dari zaman dahulu sampai sekarang.

e. Kesatuan kepribadian manusia. Mereka semua diciptakan dari tanah dan ruh Ilahi.

f. Kesatuan individu dan masyarakat, masing-masing harus saling menunjang. ${ }^{10}$

Seperti dimaklumi, bahwa dalam proses pendidikan tidak hanya berupa aktivitas transfer pengetahuan dan keahlian, tetapi juga merupakan aktivitas transfer nilai-ilai dan kebudayaan. Dalam Islam prosses pendidikan dalam rangka mengembagkan potensi-potensi manusia secara utuh dan seimbang, ditekankan mulai dalam kehidupan keluarga.

9 Abdul Mujib dan Mudzakkir Jusuf ,Op. Cit., hlm. 65

10 Nata, Abuddin.2003.Manajemen Pendidikan (Mengatasi Kelemahan Pendidikan Islam di Indonesia).Jakarta: Kencana, hlm. 182 
Rumah tangga atau keluarga sebagai pranata (institusi) kependidikan dipandang sangat strategis, terutama dalam membentuk watak dan kepribadian manusia. Bahkan, Islam menyatakan apapun pandangan hidup, keyakinan dan perilaku seseorang, tidak dapat lepas dari tanggung jawab kedua orang tuanya. ${ }^{11}$

Dengan pandanagn demikian, Islam menilai bahwa intervensi instrumental pertama yang akan mengkontaminasi kepribadian manusia, juga berasal atau bersumber dari lingkungan sosial, dalam konteks ini adalah keluarga. Data-data empiris juga membuktikan bahwa lingkungan keluarga yang berantakan banyak berpengaruh terhadap kepribadian anak-anaknya. Padahal kepribadian merupakan salah satu parameter kualitas sumber daya manusia. Tapi sayangnya peranan keluarga sebagai pranata pendidikan dalam masyarakat modern sekarang menunjukkan tendensi melemah. ${ }^{12}$

\section{Pengembangan Sumber Daya Manusia Melalui Pendidikan}

Pendidikan pada dasarnya merupakan usaha pengembangan sumber daya manusia (SDM). Meskipun pengembangan SDM bukan hanya dilakukan melalui pendidikan, khususnya pendidikan formal tetapi sampai saat ini dipercayai bahwa pendidikan merupakan wahana utama untuk mengembagkan SDM, yang dilakukan secara sistematis, terprogram, dan berjenjang. Dalam konteks inilah pendidikan akan semakin dituntut peranannya dalam pembangunan bangsa, untuk menghasilkan manusia Indonesia yang berkualitas. Sedangkan ciri-ciri manusia Indonesia yang berkualitas yang diidealkan itu di deskripsikan secara jelas dalam UndangUndang Nomor 20 tahun 2003 tentang Sistem Pendidikan Nasional dan penjelasannya yaitu: beriman dan bertakwa terhadap Tuhan Yang Maha Esa, berbudi pekerti luhur, berkepribadian, mandiri, maju, tangguh, cerdas, kreatif, terampil, berdisiplin, beretos kerja, profesional, bertanggungjawab, dan produktif serta sehat rohani dan jasmani, berjiwa patriotik, cinta tanah air, mempunyai semangat kebangsaan, kesetiakawanan sosial, kesadaran

\footnotetext{
${ }^{11}$ Ibid., hlm. 203

${ }^{12}$ Ibid., hlm. 222
} 
pada sejarah bangsa, menghargai jasa pahlawan dan berorientasi masa depan. ${ }^{13}$

Mungkin di antara kita ada yang ingin meminimalkan formulasi ciriciri tersebut, dengan mengatakan, bahwa SDM yang harus diupayakan melalui pendidikan adalah yang bercirikan:

1) Beriman dan bertaqwa kepada Tuhan Yang Maha Esa

2) Kreatif

3) Produktif

4) Berkepribadian tanpa mengabaikan makna yang terkandung dalam ciri-ciri yang tercantum dalam Sistem Pendidikan Nasional.

Untuk itu semua, jelaslah bahwa pengembangan SDM tidak mungkin cukup hanya mengembangkan potensi akal dan jasad saja, tanpa memperhatikan pengembangan potensi qalbu (hati nurani), yaitu potensi yag akan mengembangkan spiritual manusia, moral etika, estetika dan sikap-sikap serta perilaku positif lainnya. Keunggulan inteletualitas dan profesionalitas yang dihasilkan oleh iptek melalui potensi akal, jika tidak diimbagi secara ketat dengan keunggulan spiritualitas dan moralitas, maka yang terjadi hanyalah sekumpulan SDM yang hanya mempertanyakan sesuatu yang berdasarkan keunggulan intelektualitas dan profesionalitas. Untuk itu penekanan utama pengembangan SDM adalah kepada sikap dan perilaku yang mengacu kepada moralitas dan spiritualitas yang kuat.

Sangat menarik pernyataan mantan Mendikbud RI, Prof. Wadirman Djoyonegoro bahwa bagaimana output pendidikan itu memiliki link (keterkaitan) dengan kebutuhan masyarakat. Dalam hal ini pendidikan harus dapat menghasilkan manusia ilmu dan teknologi. SDM yang berkualitas yang diinginkan, minimal mempunyai dua macam kompetensi. ${ }^{14}$ Yakni komptensi iptek (ilmu pengetahuan dan tehnologi) dan kompetensi imtak (iman dan takwa).

Dengan sendirinya yang dimaksud adalah adanya saling mendukung antara dua macam kompetensi tersebut pada SDM dan bukan mengumpulkan dua kompetensi yang dikotomis. Kompetensi iptek

13 Putra Daulay, Haidar.Op.Cit., hlm. 17

14 Putra Daulay, Haidar. 2004.Pendidikan Islam. .Jakarta: Kencana Prenada Media,hlm. 206 
berperan mengaktualisasikan idiom dan doktrin-doktrin imtak dan kompetensi imtak berperan memoralisasikan penerapan dan tujuan-tujuan iptek. Sebab kecanggihan iptek yang tanpa disertai disiplin moral banyak menimbulkan tragedi kemanusiaan dalam perjalanan sejarah peradaban manusia selama ini.

\section{Penutup}

Manusia dalam pandangan Islam merupakan makhluk unggulan, yang dibekali beberapa potensi, yaitu akal, kalbu, dan jasad. Potensipotensi tersebut harus dikembangkan dalam rangka pencapaian kompetensi-kompetensi yang memungkinkan manusia melakukan tugas esensialnya dalam hidupnya, yaitu ibadah kepada Tuhan dan khalifah dari Tuhan.

Pendidikan pada dasarnya merupakan usahan pengembangan sumber daya manusia, yang dilakukan secara sistematis, terprogram dan berjenjang, agar dapat menghasilkan manusia-manusia yang berkualitas, yang dapat memberikan manfaat, dan sekaligus meningkatkan harkat dan martabatnya.

Pendidikan Islam berarti suatu proses yang komprehensif dari pengembangan kepribadian manusia secara keseluruhan,yang meliputi: intelektual, spiritual, emosi, dan fisik, sehingga seorang muslim disiapkan dengan baik untuk memiliki kemampuan mengaktualisasikan potensipotensinya, dan berkompeten melaksanakan tugas-tugas esensialnya, dalam kehidupan individu maupun kolektif. Semua itu merupakan perwujudan dari upaya pendekatan diri dan pengabdian kepada Tuhan. Peran iptek dan imtak dalam pengembangan kualitas SDM sangat besar, apabila keduanya saling mendukung dan mengisi. 


\section{DAFTAR PUSTAKA}

Abdusshomad, Muhyiddin. 2005. Penuntun Qolbu (Kiat Meraih Kecerdasan Spiritual). Surabaya: Khalista

Mujib, Abdul dan Jusuf, Mudzakkir. 2006. Ilmu Pendidikan Islam. Jakarta: Kencana

Nata, Abuddin. 2003. Manajemen Pendidikan ( Mengatasi Kelemahan Pendidikan Islam di Indonesia). Jakarta: Kencana

Putra Daulay, Haidar. 2004. Pendidikan Islam dalam Sistem Pendidikan Nasional. Jakarta: Kencana

Suhartono, Suparlan. 2005. Filsafat Ilmu Pengetahuan. Jogjakarta: Ar-Ruz.

Tholhah Hasan, Muhammad.1995. Makalah Seminar Nasional Pendidikan oleh PP.Lembaga Pendidikan Ma'arif 